\title{
Underdiagnosis of delirium on admission and prediction of patients who will develop delirium during their inpatient stay: a pilot study
}

Yuin Cheng $\underline{\text { Chin }}^{1}$, MBBs, Gerald Choon Huat $\underline{K o h}^{2}$, MMed, PhD, Yee Kian $\underline{\operatorname{Tay}}{ }^{3}, \mathrm{MN}$, Chay Hoon $\underline{\operatorname{Tan}}^{4}$, MMed, PhD, Reshma Aziz Merchant ${ }^{1}$, MBChB, FRCP

INTRODUCTION The study aimed to determine the prevalence and documentation of delirium among the elderly and if the Clock Drawing Test (CDT) can be used to predict which patients had delirium on admission and those who may develop delirium during their stay in acute medical wards.

METHODS A single researcher performed the Mini-Mental State Examination (MMSE) and CDT on admission and discharge of 57 elderly adults at the National University Hospital, Singapore. Delirium was defined as a $\geq 3$-point improvement or $\geq 2$-point decline in MMSE scores from admission to discharge, where a fall denotes development of delirium and a rise denotes resolution. The case notes of the same patients were reviewed for documentation of delirium. All inpatients from two acute medical wards were examined. One CDT score and a pair of MMSE scores were collected from each patient. RESULTS A total of 57 patients ( 28 male, 29 female) were involved in the study. Their mean age was $76.0 \pm 8.7$ years. The prevalence of delirium based on MMSE scores was $40.4 \%$; 16 patients had delirium on admission while seven developed delirium during their inpatient stay. However, delirium was documented in the case notes of only 7 (30\%) of the 23 patients. CDT score was better than baseline MMSE score at predicting a decline in MMSE score.

CONCLUSION The prevalence of delirium in the acute medical setting is high but underdiagnosed. The CDT may be a good screening tool to identify patients at risk of delirium during their inpatient stay. Baseline cognition screening should be performed in every elderly patient admitted to hospital.

Keywords: clock drawing test, cognitive impairment in medical wards, delirium, elderly inpatients

\section{INTRODUCTION}

Delirium, defined by $\mathrm{O}^{\prime}$ Keeffe as a $\geq 3$-point improvement or $\geq 2$-point decline in Mini-Mental State Examination (MMSE) scores from admission to discharge, where a fall denotes development of delirium and a rise denotes resolution, ${ }^{(1)}$ is a reversible mental disorder that is often caused by multiple factors. ${ }^{(2,3)}$ Proper identification and treatment can prevent increased healthcare costs, ${ }^{(4-6)}$ prolonged hospital stay ${ }^{(5)}$ and increased likelihood of placement in a nursing home on discharge. ${ }^{(7,8)}$ Studies on delirium conducted in the hospital setting have found that it is the single most common acute mental disorder among hospitalised elderly patients. ${ }^{(9-11)}$ Prospective studies of medical inpatients in Western countries reported a prevalence of delirium (i.e. existing cases on hospital admission) of $12 \%-31 \%^{(12,13)}$ and incidence rates (i.e. new cases arising during the hospital stay) of $3 \%-25 \% .^{(5,14)}$ It has also been reported that about $30 \%$ of elderly patients experience delirium at some time during hospitalisation. ${ }^{(15,16)}$ Despite its frequent occurrence and significant consequences, delirium is often underrecognised. It is not detected by healthcare personnel in up to $70 \%$ of patients ${ }^{(17)}$ and is often unrecognised on hospital admission. ${ }^{(18)}$

We hypothesised that the primary team often misses the diagnosis of delirium when managing elderly patients admitted to the acute medical ward. This study aimed to determine the prevalence and rate of underreporting of delirium among elderly patients admitted to the acute medical wards of a tertiary hospital in Singapore, and to compare the ability of two cognitive screening tests, the MMSE and the Clock Drawing Test (CDT), to predict the development or resolution of delirium during hospitalisation.

\section{METHODS}

A single researcher conducted the MMSE and CDT for 57 patients aged $\geq 60$ years who were admitted to two acute medical wards in the National University Hospital, Singapore, in June 2011 and June 2012. The MMSE was performed within 24 hours of admission and discharge, and the CDT was performed within 24 hours of admission. Patients were excluded if they were uncommunicative, had a severe hearing impairment or were discharged within 24 hours of admission.

The MMSE is a 20-item test that screens for cognitive impairment. ${ }^{(1,19)}$ It has a total score of 30 points. The items are clustered into 11 subscores measuring orientation to time (maximum possible score $[\max ] 5$ ), orientation to location $(\max 5)$, immediate recall $(\max 3)$, attention and calculation $(\max 5)$, delayed recall $(\max 3)$, naming $(\max 2)$, verbal repetition $(\max 1)$, ability to follow a three-stage command $(\max 3)$, reading $(\max 1)$, writing $(\max 1)$ and figure-copying

\footnotetext{
${ }^{1}$ Department of Medicine, Yong Loo Lin School of Medicine, ${ }^{2}$ Saw Swee Hock School of Public Health, National University of Singapore, ${ }^{3}$ Department of Nursing, National University Hospital, ${ }^{4}$ Department of Psychiatric Medicine, Yong Loo Lin School of Medicine, National University of Singapore, Singapore

Correspondence: Assoc Prof Reshma Aziz Merchant, Head and Senior Consultant, Division of Advanced Internal Medicine, National University Hospital, 5 Lower Kent Ridge Road, Singapore 119074. reshmaa@nuhs.edu.sg
} 
Table I. Summary of changes in Mini-Mental State Examination (MMSE) scores on discharge and case note documentation on the patients $(n=57)$.

\begin{tabular}{|c|c|c|c|c|c|c|c|c|}
\hline & \multicolumn{8}{|c|}{ No. (\%) } \\
\hline & \multicolumn{4}{|c|}{ Normal MMSE score $(n=26)^{+}$} & \multicolumn{4}{|c|}{ Abnormal MMSE score $(n=31)^{+}$} \\
\hline & $\begin{array}{l}\text { Improved by } \\
\geq 3 \text { points }\end{array}$ & $\begin{array}{l}\text { Remained } \\
\text { equivocal }\end{array}$ & $\begin{array}{l}\text { Worsened by } \\
\geq 2 \text { points }\end{array}$ & Total & $\begin{array}{l}\text { Improved by } \\
\geq 3 \text { points }\end{array}$ & $\begin{array}{l}\text { Remained } \\
\text { equivocal }\end{array}$ & $\begin{array}{l}\text { Worsened by } \\
\geq 2 \text { points }\end{array}$ & Total \\
\hline Change in MMSE score & $2(7.7)$ & $21(80.8)$ & $3(11.5)$ & $26(100)$ & $14(45.2)$ & $13(41.9)$ & $4(12.9)$ & $31(100)$ \\
\hline $\begin{array}{l}\text { Clinical documentation } \\
\text { of cognitive impairment* }\end{array}$ & 0 & 3 & 1 & 4 & 3 & 6 & 4 & 13 \\
\hline $\begin{array}{l}\text { Clinical documentation } \\
\text { of delirium }\end{array}$ & 0 & 1 & 0 & 1 & 1 & 3 & 2 & 6 \\
\hline
\end{tabular}

*Includes dementia. ${ }^{\text {Defined }}$ using MMSE scores and educational level cutoffs.

(max 1). Cognitive impairment was defined using MMSE scores and education-adjusted cutoffs ${ }^{(20)}$ of $<21$ points for patients with $<6$ years of education, $<23$ points for patients with $6-12$ years of education and $<24$ points for patients with $>12$ years of education (Appendix I).

For the CDT, we used the scoring method adapted by Shulman et al from Cahn et al. ${ }^{(21-24)}$ The instructions given to the patients and scoring system used (range 1-5, with 5 being normal) are shown in Appendix II. Although a cutoff score of $\leq 3$ out of 5 was recommended by Shulman et $\mathrm{al}^{(24,25)}$ as an indicator of cognitive impairment, local research has found that a cutoff score of $\leq 4$ out of 5 was more appropriate. ${ }^{(26)}$ We did not use the CDT as the primary measure of delirium because it has not been validated by any study as a tool to detect delirium. Instead, we compared it with the MMSE as a cognitive screening test at admission to predict the development or resolution of delirium during hospitalisation, using $\mathrm{O}^{\prime}$ Keeffe et al's definition. ${ }^{(1)}$ The primary team made the diagnosis of delirium mainly through clinical assessment of the patient. The case notes and discharge summaries of each patient were reviewed retrospectively for documentation of cognitive impairment and/or delirium.

Demographic and clinical characteristics of the patients that involved categorical variables were summarised using counts and percentages. For continuous variables, mean and standard deviation were used to describe the data distribution. The primary outcome variable was the development or resolution of delirium during hospitalisation and was based on O'Keeffe et al's definition of either (a) an improvement in MMSE score by $\geq 3$ points to detect resolution of delirium; or (b) decline in MMSE score by $\geq 2$ points from admission to discharge to detect development of delirium. ${ }^{(1)}$ A change in MMSE score between -1 and +2 is considered equivocal. We used the chi-square test to examine the association between cognitive status on admission (measured by MMSE/CDT score) and change in MMSE score on discharge, as well as the association between change in MMSE score on discharge and re-admission rates up to three months after discharge. We examined the independent associations of CDT and MMSE scores at admission compared to change in MMSE score on discharge using logistic regression. All statistical analyses were generated using IBM SPSS Statistics version 20.0 (IBM Corp, Armonk, NY, USA), using a two-sided test at a 5\% level of significance.

\section{RESULTS}

A total of 57 pairs of MMSE scores were collected from 28 (49\%) male and 29 (51\%) female patients. Their mean age was $76.0 \pm 8.7$ years and the mean length of hospital stay was $6.0 \pm 3.3$ days. On admission, $26(46 \%)$ of the 57 patients had MMSE scores within the normal range, while 31 (54\%) patients had impaired MMSE scores (Table I).

On discharge, regardless of their cognitive state on admission, the MMSE scores of 16 (28.1\%) patients had an improvement of $\geq$ 3 points and $7(12.3 \%$ ) patients had a decline of $\geq 2$ points (Table I). Hence, based on the criteria for delirium, 23 (40.4\%) patients had either developed delirium or recovered from delirium during their hospital stay. Of the 31 patients who had cognitive impairment on admission (i.e. abnormal MMSE scores), 14 (45.2\%) patients improved by $\geq 3$ points, $13(41.9 \%)$ remained equivocal and $4(12.9 \%)$ worsened by $\geq 2$ points. Out of the 26 patients who had no cognitive impairment on admission (i.e. normal MMSE scores), 2 (7.7\%) patients improved by $\geq 3$ points, 21 (80.8\%) remained equivocal and 3 (11.5\%) worsened by $\geq 2$ points. Of the 23 patients who improved by $\geq 3$ points or worsened by $\geq 2$ points, only $3(13.0 \%)$ patients had documentation of delirium in their case notes. Mean MMSE scores on admission for the three groups of patients whose score worsened, was equivocal or improved were $19.7 \pm 7.9,23.6 \pm 4.3$ and $17.9 \pm 5.2$ points, respectively, while mean MMSE scores on discharge were 16.0 $\pm 7.6,24.5 \pm 4.4$ and $22.9 \pm 6.0$ points, respectively.

Among the 16 patients who had a CDT score of $0-3$ points on admission, 4 (25.0\%) worsened by $\geq 2$ points, 6 (37.5\%) remained equivocal and $6(37.5 \%)$ improved by $\geq 3$ points in their MMSE scores on discharge (Table II). Among the six patients who had a CDT score of 4 points on admission, 1 (16.6\%) worsened by $\geq 2$ points, 2 (33.3\%) remained equivocal and 3 (50.0\%) improved by $\geq 3$ points in their MMSE scores on discharge. Among the 25 patients who had a CDT score of 5 points on admission, $2(8.0 \%)$ worsened by $\geq 2$ points, $20(80.0 \%)$ remained equivocal and $3(12.0 \%)$ improved by $\geq 3$ points in their MMSE scores on discharge.

Logistic regression analysis adjusted for age, gender and ethnicity showed that normal cognition, assessed according to the patient's MMSE score on admission, was a predictor of absence of delirium or resolution of delirium during the hospital stay, i.e. an equivocal change in MMSE score (odds ratio [OR] 
Table II. Relationship between Clock Drawing Test (CDT) score on admission and change in Mini-Mental State Examination (MMSE) score on discharge.

\begin{tabular}{lcccr}
\hline $\begin{array}{l}\text { CDT score on } \\
\text { admission }\end{array}$ & \multicolumn{4}{c}{ Change in MMSE score on discharge $(\mathbf{n}=\mathbf{4 7})^{*}$} \\
\cline { 2 - 5 } & Improved by $\geq 3$ points & Remained equivocal & Worsened by $\geq 2$ points & Total \\
\hline 0 & $1(50.0)$ & 0 & $1(50.0)$ & $2(100)$ \\
1 & 0 & $4(57.1)$ & $3(42.9)$ & $7(100)$ \\
2 & $1(100.0)$ & 0 & 0 & $1(100)$ \\
3 & $4(67.7)$ & $2(33.3)$ & 0 & $6(100)$ \\
4 & $3(50.0)$ & $2(33.3)$ & $1(16.7)$ & $6(100)$ \\
5 & $3(12.0)$ & $20(80.0)$ & $2(8.0)$ & $25(100)$ \\
\hline
\end{tabular}

Data presented as no. (\%). * Some patients were not able to perform CDT.

Table III. Comparison of Mini-Mental State Examination (MMSE) and Clock Drawing Test (CDT) scores at admission predicting improvement in cognition on discharge.

\begin{tabular}{llrr}
\hline Dependent variable* $^{*}$ & Independent variable & Effect size (95\% CI) & p-value \\
\hline MMSE score improved by $\geq 3$ points & CDT score on admission & $0.13(-0.44 \text { to } 0.70)^{\ddagger}$ & 0.659 \\
& No cognitive impairment vs. cognitive impairment ${ }^{+}$ & $0.74(0.10 \text { to } 0.57)^{\S}$ & 0.012 \\
MMSE score worsened by $\geq 2$ points & CDT score on admission & $-1.15(-2.26 \text { to }-0.03)^{\ddagger}$ & 0.045 \\
& No cognitive impairment vs. cognitive impairment ${ }^{+}$ & $12.1(0.16 \text { to } 911.93)^{\S}$ & 0.258 \\
\hline
\end{tabular}

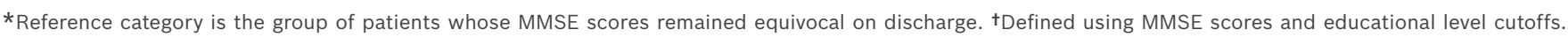
\#Beta coefficient reported. §odds ratio reported.

$0.74,95 \%$ confidence interval $[\mathrm{Cl}] 0.10$ to $0.57, \mathrm{p}=0.012)$. CDT score on admission in itself was not a predictor of delirium during the hospital stay $(B=0.13,95 \% \mathrm{Cl}-0.44$ to $0.70, \mathrm{p}=0.659$ ) (Table III). However, a lower CDT score on admission was a predictor of worsening MMSE score $(B=-1.15,95 \% \mathrm{Cl}-2.26$ to $-0.03, \mathrm{p}=0.045)$, while a lower MMSE score on admission was not a predictor (OR 12.1, 95\% Cl 0.16 to $911.93, \mathrm{p}=0.258$ ).

\section{DISCUSSION}

In our study, the prevalence of delirium was $28.1 \%$ on admission to the acute medical ward and $12.3 \%$ of the patients developed delirium during their stay. This is comparable with international data from well-established hospitals, which showed that the prevalence of delirium in medical inpatients on admission was between $12 \%$ and $31 \%,{ }^{(12,13)}$ and the development of delirium during admission was 3\%-25\%. ${ }^{(5,14)}$ However, less than onethird of the patients who had delirium in the present study were documented to have this condition, suggesting that delirium is often overlooked in the day-to-day care of elderly patients admitted to acute medical wards. Previous studies have found that delirium is overlooked in up to $68 \%$ of patients. ${ }^{(27)}$ It has been reported that untreated delirium increases mortality rates up to three-fold, increases the chance of discharge to nursing home and increases long-term cognitive impairment by up to ten times. ${ }^{(5,12,28,29)}$ As age is a major predisposing factor for delirium, failing to diagnose delirium will increase the economic burden of caring for elderly patients in Singapore's ageing population.

Our study also showed that a normal MMSE score at admission was a better predictor than the CDT score of the absence of delirium during hospitalisation. On the other hand, a lower CDT score was better than the MMSE score in predicting patients whose MMSE score would worsen on discharge. Our findings suggest that the CDT is a good screening tool to detect those at high risk of developing delirium during their inpatient stay. However, this finding should be confirmed by a larger study using a gold-standard diagnostic tool for delirium, such as the Confusion Assessment Method. ${ }^{(8)}$

The strength of this pilot study was that the data was collected by a single researcher, hence reducing random error and interviewer bias. Its limitations were the small sample size and lack of correlation with the use of catheters and restraints, anticholinergic burden of medications in patients, and underlying function or principal diagnosis for admission. In addition, the correlation between these methods of measuring cognitive changes and the Confusion Assessment Method was not assessed. The test-retest reliability of the MMSE as a screening tool may also be a concern; however, studies have shown that the amount of change in MMSE score was small, usually less than 2 points. ${ }^{(30)}$ Another major limitation of the study is that MMSE scores could have remained equivocal (i.e. did not change) for the patients who were delirious at admission and remained so at discharge.

Our study confirmed that the prevalence of delirium is $40 \%$ among older adult inpatients admitted to acute medical wards, and that delirium was overlooked in $70 \%$ of these patients. Interestingly, we found that the CDT is better at predicting patients who will develop delirium during their inpatient stay than the baseline MMSE. We found no statistical difference in terms of length of stay and re-admission rates between those with normal or impaired MMSE scores. As delirium is often overlooked by medical professionals but is an important prognostic indicator, all older adults admitted to acute hospitals should be screened for underlying cognitive impairment and delirium. Further largerscale studies are required to evaluate if the CDT can be used as a screening tool to identify older adults at risk of developing delirium in hospitals. 


\section{ACKNOWLEDGEMENTS}

The authors would like to thank A/Prof Tai Bee Choo and Mr Benjamin Er from the Saw Swee Hock School of Public Health, National University of Singapore, Singapore, for advising in statistical analysis for this paper.

\section{REFERENCES}

1. O'Keeffe ST, Mulkerrin EC, Nayeem K, Varughese M, Pillay I. Use of serial Mini-Mental State Examinations to diagnose and monitor delirium in elderly hospital patients. J Am Geriatr Soc 2005; 53:867-70.

2. American Psychiatric Association. Diagnostic and Statistical Manual of Mental Disorders: DSM-IV. 4th ed. Washington, DC: American Psychiatric Association, 1994.

3. Fick DM, Agostini JV, Inouye SK. Delirium superimposed on dementia: a systematic review. J Am Geriatr Soc 2002; 50:1723-32.

4. Pompei $P$, Foreman M, Rudberg MA, et al. Delirium in hospitalized older persons: outcomes and predictors. J Am Geriatr Soc 1994; 42:809-15.

5. O'Keeffe S, Lavan J. The prognostic significance of delirium in older hospital patients. J Am Geriatr Soc 1997; 45:174-8.

6. Inouye SK. The dilemma of delirium: clinical and research controversies regarding diagnosis and evaluation of delirium in hospitalized elderly medical patients. Am J Med 1994; 97:278-88.

7. Fields SD, MacKenzie CR, Charlson ME, Sax FL. Cognitive impairment. Can it predict the course of hospitalized patients? J Am Geriatr Soc 1986 34:579-85.

8. Inouye SK, van Dyck $\mathrm{CH}$, Alessi CA, et al. Clarifying confusion: the confusion assessment method. A new method for detection of delirium. Ann Intern Med 1990; 113:941-8.

9. Inouye SK. Predisposing and precipitating factors for delirium in hospitalized older patients. Dement Geriatr Cogn Disord 1999; 10:393-400.

10. Wahlund L, Björlin GA. Delirium in clinical practice: experiences from a specialized delirium ward. Dement Geriatr Cogn Disord 1999; 10:389-92.

11. Eikelenboom P, Hoogendijk WJ. Do delirium and Alzheimer's dementia share specific pathogenetic mechanisms? Dement Geriatr Cogn Disord 1999; 10:319-24.

12. Cole MG, Dendukuri N, McCusker J, Han L. An empirical study of different diagnostic criteria for delirium among elderly medical inpatients. J Neuropsychiatry Clin Neurosci 2003; 15:200-7.

13. Cole MG, McCusker J, Bellavance F, et al. Systematic detection and multidisciplinary care of delirium in older medical inpatients: a randomized trial. CMAJ 2002; 167:753-9.

14. Inouye SK, Viscoli CM, Horwitz RI, Hurst LD, Tinetti ME. A predictive model for delirium in hospitalized elderly medical patients based on admission characteristics. Ann Int Med 1993; 119:474-81.

15. Francis J. Delirium in older patients. J Am Geriatr Soc 1992; 40:829-38.

16. Inouye SK, Rushing JT, Foreman MD, Palmer RM, Pompei P. Does delirium contribute to poor hospital outcomes? A three-site epidemiologic study. J Gen Intern Med 1998; 13:234-42.

17. Inouye SK, Foreman MD, Mion LC, Katz KH, Cooney LM Jr. Nurses' recognition of delirium and its symptoms: comparison of nurse and researcher ratings. Arch Intern Med 2001; 161:2467-73.

18. Pisani MA, Redlich C, McNicoll L, Ely EW, Inouye SK. Underrecognition of preexisting cognitive impairment by physicians in older ICU patients. Chest 2003; 124:2267-74

19. Folstein MF, Folstein SE, McHugh PR. "Mini-mental state". A practical method for grading the cognitive state of patients for the clinician. J Psychiatr Res 1975; 12:189-98.

20. Uhlmann RF, Larson EB. Effect of education on the mini-mental state examination as a screening test for dementia. J Am Geriatr Soc 1991; 39:876-80.

21. Shulman KI, Shedletsky R, Silver IL. The challenge of time: Clock-drawing and cognitive function in the elderly. Int J Geriatr Psychiatry 1986; 1:135-40.

22. Tuokko H, Hadjistavropoulos T, Miller JA, Beattie BL. The Clock Test: a sensitive measure to differentiate normal elderly from those with Alzheimer disease. J Am Geriatr Soc 1992; 40:579-84.

23. Cahn DA, Salmon DP, Monsch AU, et al. Screening for dementia of the alzheimer type in the community: the utility of the Clock Drawing Test. Arch Clin Neuropsychol 1996; 11:529-39.

24. Shulman KI, Gold DP, Cohen CA, Zucchero CA. Clock-drawing and dementia in the community: A longitudinal study. Int J Geriatr Psychiatry 1993; 8:487-96.

25. Shulman KI. Clock-drawing: is it the ideal cognitive screening test? Int J Geriatr Psychiatry 2000; 15:548-61.

26. Munang LA, Chan M, Lim WS. Diagnostic performance of the Clock Drawing Test using a pre-drawn circle in persons with early dementia. Asian J Gerontol Geriatr 2010; 5:54-61.

27. Carrasco M, Hoyl T, Marín PP, et al. [Delirium in Chilean elderly inpatients: an overlooked problem]. Rev Med Chil 2005; 133:1449-54. Spanish.

28. Francis J, Kapoor WN. Prognosis after hospital discharge of older medical patients with delirium. J Am Geriatr Soc 1992; 40:601-6.

29. Gustafson Y, Berggren D, Brännström B, et al. Acute confusional states in elderly patients treated for femoral neck fracture. J Am Geriatr Soc 1988; 36:525-30.

30. Tombaugh TN, Mclntyre NJ. The mini-mental state examination: a comprehensive review. J Am Geriatr Soc 1992; 40:922-35.

\section{APPENDIX}

Table I. Education-adjusted cutoff scores using Mini-Mental State Examination scores to define cognitive impairment.

\begin{tabular}{lc}
\hline No. of years of education & Cutoff score \\
\hline$<6$ & $<21$ \\
$6-12$ & $<23$ \\
$>12$ & $<24$ \\
\hline
\end{tabular}

Table II. Instructions and scoring system for the Clock Drawing Test.

\begin{tabular}{ll}
\hline Instructions & Scoring system \\
\hline Draw a big circle & $\cdot 1$ point \\
Fill in the numbers & $\cdot 1$ point for correct numbers written \\
of the clock & -1 point for correct positioning of \\
& the numbers \\
Draw in the hands & -1 point if two hands of the clock \\
of the clock for & were drawn \\
ten past 11 & -1 point for the correct time \\
\hline
\end{tabular}

